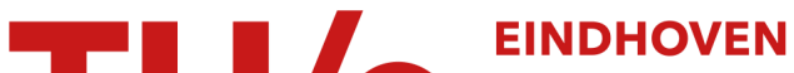 \\ UNIVERSITY OF \\ TECHNOLOGY
}

\section{Marginal regeneration of a mobile vertical free liquid film}

\author{
Citation for published version (APA): \\ Hudales, J. B. M., \& Stein, H. N. (1990). Marginal regeneration of a mobile vertical free liquid film. Journal of \\ Colloid and Interface Science, 138(2), 354-364. https://doi.org/10.1016/0021-9797(90)90218-D
}

DOI:

10.1016/0021-9797(90)90218-D

Document status and date:

Published: 01/01/1990

\section{Document Version:}

Publisher's PDF, also known as Version of Record (includes final page, issue and volume numbers)

\section{Please check the document version of this publication:}

- A submitted manuscript is the version of the article upon submission and before peer-review. There can be important differences between the submitted version and the official published version of record. People interested in the research are advised to contact the author for the final version of the publication, or visit the $\mathrm{DOI}$ to the publisher's website.

- The final author version and the galley proof are versions of the publication after peer review.

- The final published version features the final layout of the paper including the volume, issue and page numbers.

Link to publication

\section{General rights}

Copyright and moral rights for the publications made accessible in the public portal are retained by the authors and/or other copyright owners and it is a condition of accessing publications that users recognise and abide by the legal requirements associated with these rights.

- Users may download and print one copy of any publication from the public portal for the purpose of private study or research.

- You may not further distribute the material or use it for any profit-making activity or commercial gain

- You may freely distribute the URL identifying the publication in the public portal.

If the publication is distributed under the terms of Article $25 \mathrm{fa}$ of the Dutch Copyright Act, indicated by the "Taverne" license above, please follow below link for the End User Agreement:

www.tue.nl/taverne

Take down policy

If you believe that this document breaches copyright please contact us at:

openaccess@tue.nl

providing details and we will investigate your claim. 


\title{
Marginal Regeneration of a Mobile Vertical Free Liquid Film
}

\author{
J. B. M. HUDALES AND H. N. STEIN ${ }^{1}$ \\ Laboratory of Colloid Chemistry, Eindhoven University of Technology, \\ P.O. Box 513, 5600 MB Eindhoven, the Netherlands
}

Received July 17, 1989; accepted December 19, 1989

\begin{abstract}
Marginal regeneration is the main thinning mechanism of a mobile vertical free liquid film, whereby thicker film regions, including the surfaces, are sucked in by the Plateau border, in exchange for thinner regions in an immediately adjacent section. Its hydrodynamic theory is confirmed by calculations performed on profiles of films, drawn from a $0.02 \mathrm{MCTAB}$ solution, where the net flow out of the film is described as a result of a surface flow combined with a bulk flow caused by a pressure gradient. (C) 1990 Academic Press, Inc
\end{abstract}

\section{INTRODUCTION}

Although vertical free liquid films have been investigated for a long time already (for an extended bibliography of early investigations, see Ref. (1)), the principles of their drainage still are not fully understood. Drainage has been studied extensively in the case of horizontal films (2-4); however, investigations of vertical films focused on Frankel's law for film formation $(1,5-8)$, black films $(9-21)$, bursting (22-25), film contact angles (26-31), and surface waves (32-42), the last subject being treated mainly theoretically. Only a few papers dealt with actual flow in free films $(10,43-$ 45 ) and Plateau borders (46), but the physics of the main drainage mechanism for mobile films, viz., marginal regeneration $(1,7)$, remained unsolved. Recently, several new techniques for the measurement of film thickness were developed $(45,47)$.

During marginal regeneration thicker parts of a film are withdrawn into the adjacent Plateau border and replaced by thinner parts generated from the same Plateau border at neighboring spots (1), while the total surface area of the film does not change significantly. This exchange of thinner for thicker film parts results in an effective drainage of the film. Grav-

\footnotetext{
${ }^{1}$ To whom correspondence should be addressed.
}

ity influences these phenomena, because the thinner film elements formed by the marginal regeneration move to that part of the film where thicknesses match; in a horizontal film there is no systematic variation of film thickness along the border, whereas such a systematic variation is present in a vertical film. Thus, vertical films are expected to show a drainage behavior that is basically different from that found for horizontal films.

Frankel et al. (1) derived an equation for describing marginal regeneration, but to the knowledge of the present authors this equation has never been experimentally verified in a quantitative sense. It is seen that a starting point for a quantitative elaboration of this theory is the pressure in the Plateau border at a certain height. It was shown in a previous paper (48) that this is equal to the hydrostatic equilibrium pressure at a height of $11 \mathrm{~mm}$ above the meniscus, while it is lower at smaller heights. Calculations in the present paper are restricted to heights equal to or larger than 10 $\mathrm{mm}$, where the hydrostatic equilibrium pressure is assumed in the border.

\section{EXPERIMENTAL}

Materials

CTAB (Cetyltrimethylammoniumbromide; Sigma Chemical Co. The surface tension vs 
concentration graph had a distinct break near the cmc $\left(9 * 10^{-4} M(49)\right)$ without a minimum; no further purification was applied.

Twice distilled water was used to make the surfactant solutions.

\section{Apparatus}

Single free liquid foam films suspended in a glass frame were studied with a Fizeau interferometer constructed analogously to the apparatus used by Mysels (1) .

The glass frame consisted of an upper bar with a $40-\mathrm{mm}$ long leg at either end; the glass was $2 \mathrm{~mm}$ thick. Cross sections of the legs and the upper bar were made either rectangular (2 $\times 5 \mathrm{~mm}$ ) or sharp-angled by cutting the frame's inner sides at one side under an angle of $45^{\circ}$. Of the latter type, frames with different distances between the legs were available, producing $107.7,30.1,30.1,45.0$, and $15.3-\mathrm{mm}$ wide films, while the frame with rectangular legs had a width of $30.1 \mathrm{~mm}$ (measured between the inner sides of the legs).

The sample solution was contained in a glass beaker under the frame with $58-\mathrm{mm}$ height and 56-mm inner diameter; only for the $107.7-\mathrm{mm}$ frame was a beaker with 47 $\mathrm{mm}$ inner height and 124-mm inner diameter used.

Beaker and frame were positioned in a double walled metal chamber with $188-\mathrm{mm}$ inner height and 133-mm inner diameter, which was closed airtight by a P.V.C. lid. The frame was attached to a rod through the center of this lid. This rod was supplied with a ball joint in the lid, by means of which the frame could be positioned properly (i.e., perpendicular to the light beam of the Fizeau interferometer). The beaker was placed on a platform, which was also thermostated.

Before an experiment, the beaker was filled up to the edge with the sample solution and after closing the chamber with the lid to which the frame is attached, the system was left for at least $4 \mathrm{~h}$ to allow the interior of the chamber to obtain the saturated water vapor pressure at the temperature concerned, i.e., $25^{\circ} \mathrm{C}$.

A liquid film was created by first raising the platform with the beaker pneumatically to immerse the glass frame in the sample solution, and then lowering the platform within 1 sec, while leaving the lower ends of the frame in the solution. In this way a film suspended between the three frame sides and the bulk liquid was drawn.

The liquid film was observed with a home built Fizeau interferometer: it consists of a 25$\mathrm{cm}$ long metal tube (diameter $40 \mathrm{~mm}$ ) with a low pressure mercury vapor lamp (Mazda) at one end and a $25-\mathrm{cm}$ focal distance lens at the other. The latter end is inserted horizontally into a hole in the chamber in such a way that the frame containing the soap film is perpendicularly illuminated by the parallel light beam. This light is reflected from the film back into the tube and via a semireflecting mirror into a side tube, at an angle of $73^{\circ}$ with the main tube containing the ocular, to which a Minolta X-700 photo camera is connected. This camera is equipped with the standard 50$\mathrm{mm}$ object lens, a Tokina conversion lens, a close-up lens (No. 1), an Autowinder, and a programmable data back, all Minolta except for the converter. We used either 400 ASA Kodacolor or 1000 ASA Agfacolor film.

The lifetimes of foam films were measured visually with a stopwatch.

For an experiment the interference pattern of a whole film was photographed several times: the first photograph was taken at the moment the beaker reached its lowest point after film formation $(t=0)$. We usually started with six exposures, taken at $6 \mathrm{sec}$ intervals, after which the intervals were elongated more and more up to $1 \mathrm{~min}$ if the foam film was still intact. This interval elongation was applied because drainage of the film takes place at a decreasing speed. The time at which a certain photograph was taken was imprinted on it by the Multi-Function Back.

The light source emitted bluish green light, with wavelengths $440 \mathrm{~nm}$ (violet blue) and $554 \mathrm{~nm}$ (yellowish green) predominating. These colors are recognized in the interference pattern reflected by the foam film. This interference pattern consisted of many closely 
spaced, horizontal lines, which, however, did not extend quite up to the sides of the film. There the regular film thickness vs height pattern is disturbed by marginal regeneration. Here regions thinner than the film far away from the border at the same height alternate with regions thicker than this film. These lines became broader in time and moved downward when the film became thinner approaching a plane parallel to the film, whereas turbulences at the periphery of the film decreased. Because of the difference in wavelengths the green lines outnumbered the blue lines. At certain thicknesses the minima of the two wavelengths nearly coincided, resulting in a dark line. Together with the appearance of the black film at very small thickness, this phenomenon is used to determine the order of interference of all the lines observed and thus the film thickness at various heights above the bulk meniscus.

\section{RESULTS}

A typical series of profiles of one experiment is shown in Fig. 1 for a film in a $30.1-\mathrm{mm}$ frame which had legs with rectangular cross sections. Compared with the coordinate axis for the height the ordinate axis for the thickness is scaled up by a factor of about 2450 . We clearly note a bell shape for the early profiles, which becomes more and more like a wedge-shaped film. Marginal regeneration was observed at the bottom of the film and along the frame legs, turbulent at first, but gradually decreasing. The film, in its lower parts, is seen to deviate from the parabolic shape expected for rigid films, in accordance with Mysels' observations (1).

These authors studied long-living films lasting for days, although thickness measurements were performed up until $2500 \mathrm{sec}$, while our films never lived longer than $250 \mathrm{sec}$. Mysels et al. (50) suggested that the glass frame becomes dewetted more easily in the case of a cationic, strongly adsorbed surfactant than in the case of an anionic one because of the finite contact angle $\left(10^{\circ}(48)\right)$. Mysels et al. used a $0.7 \%(\sim 0.02 M)$ solution of "Santomerse No.

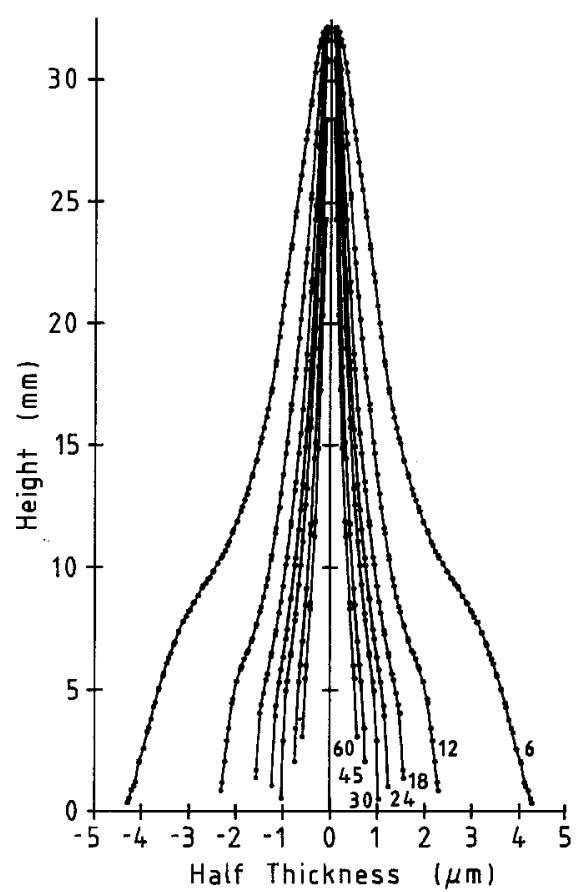

Fig. 1. Profiles of vertical liquid films in $0.02 M$ CTAB solution. Frame width: $30.1 \mathrm{~mm}$. Rectangular frame legs. Figures close to the curves are times from film formation in seconds.

1," which consisted of mixed sodium alkylbenzenesulfonates (predominantly monododecyl) containing $60 \% \mathrm{Na}_{2} \mathrm{SO}_{4}$, to produce mobile films $10 \mathrm{~cm}$ high.

This difference makes it difficult to treat our data in the same way as they did to calculate the descent constant. Indeed, they stated that the agreement of a semilogarithmic relation of height with time for a certain thickness, on which their descent constants are based, is best for relatively quiescent films, in which turbulence is moderate.

One important aspect of our films, however, was the same as that observed by Mysels et al. (1) for films formed from sodium dodecylbenzenesulfonate $+\mathrm{Na}_{2} \mathrm{SO}_{4}$ solutions: the thinning rate at given values of film thickness and height is in good approximation inversely proportional to the frame width (Fig. 2). Here the thinning rate $\left(v_{\perp}\right)$ is defined as the velocity of film surface movement in the direction perpendicular to the film plane (see below). Thus, 


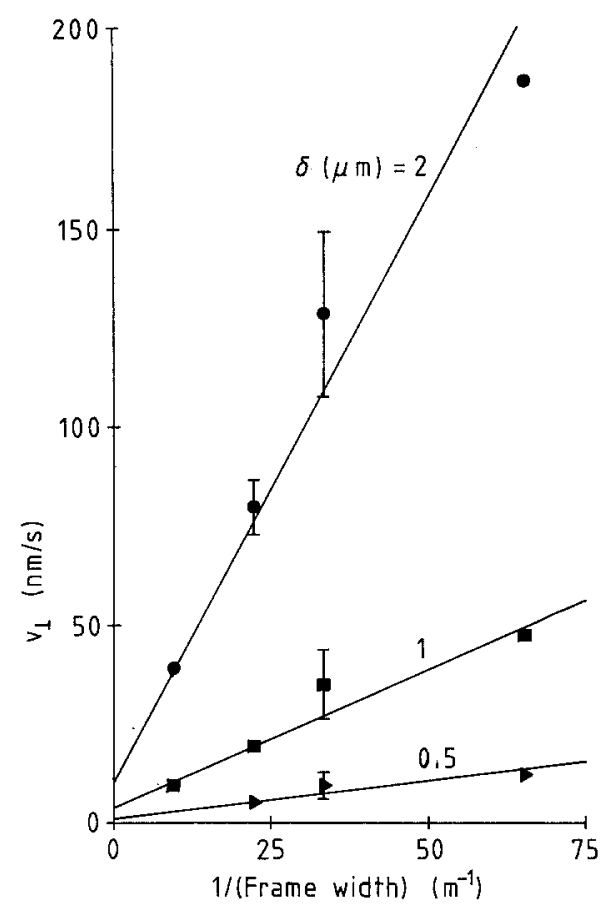

FIG. 2. Thinning rate $v_{\perp}$ (in direction perpendicular to film surface) vs reciprocal frame width $1 / b$. Sharp-angled frame legs. Height: $10 \mathrm{~mm}$. Film thickness: $\nabla, 0.5 \mu \mathrm{m}$; $\mathbf{}$, $1 \mu \mathrm{m} ; 0,2 \mu \mathrm{m}$.

horizontal drainage to the Plateau border predominates over vertical drainage to the bulk liquid.

In order to verify another aspect of the theories mentioned in (1), namely Frankel's hydrodynamic theory of marginal regeneration, we treated our data in the following way: from our profiles we linearly interpolated film thicknesses at certain heights above the bulk liquid meniscus for the times at which the photographs were taken. Through the reciprocal half film thickness vs time curves at constant height, a smoothed curve is calculated by performing a polynomial fit of maximum power 4 through the points. A typical result is shown in Fig. 3. (The reciprocal half thickness vs time curves were close to straight lines and therefore were easier to handle in the smoothing procedure than half thickness vs time curves).

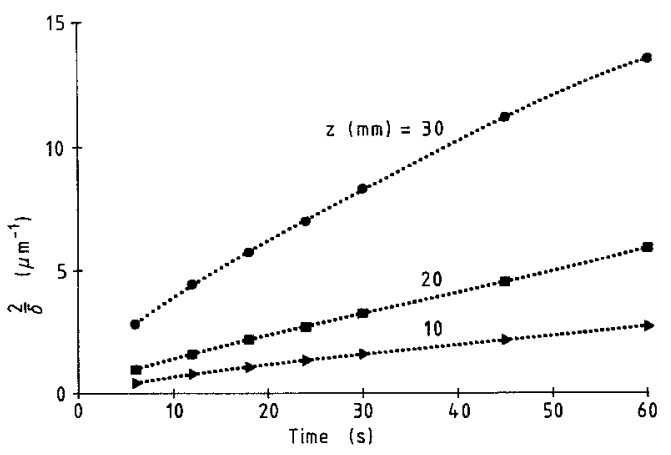

FIG. 3. Typical reciprocal half film thickness $2 / \delta$ vs time $t$ curves, employed for numerical differentiation. Rectangular frame legs.

For the many points of the smoothed curve (usually between 70 and 90, compared to 16 at most for experimental data points), the thickness is recovered and the thinning velocity $v_{\perp}$ is calculated by computing the first derivative using Lagrange's five-point interpolation formulas (51). A double-logarithmic plot of the thinning velocity $v_{\perp}$ vs film thickness usually shows a fairly straight line deviating mostly at lower thicknesses. In Fig. 4 an example is shown of such a plot. Thus, for a particular film thickness $\delta$, the drainage rate $Q$ agrees reasonably with the equation

$$
Q=k \delta^{n},
$$

where $k$ is a constant with dimension $m^{3-n} s$. From the slope of such curves, the exponent $n$ can be calculated.

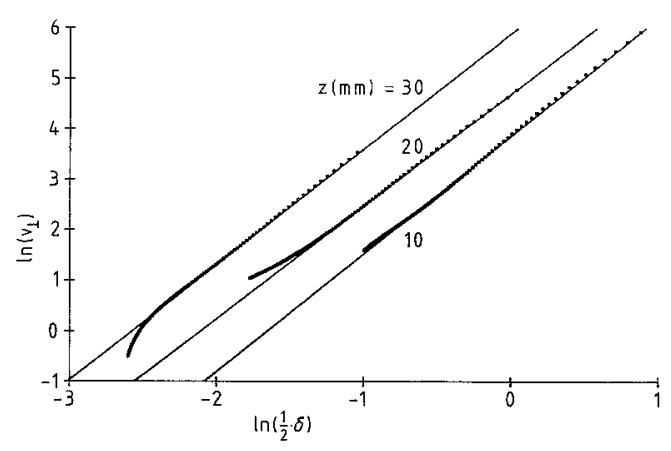

FiG. 4. Calculation of power law index $n$ (Eq. [1]) from experimental data. Same experiment as shown in Fig. 3. 
TABLE I

Values of Exponent in Power Law $Q=k * \delta^{n}$ (Eq. [1]), Derived from Experimental Data

\begin{tabular}{|c|c|c|c|c|c|}
\hline \multirow[b]{4}{*}{ Frame width (mm): } & \multicolumn{5}{|c|}{$n$} \\
\hline & \multicolumn{5}{|c|}{ Frame type } \\
\hline & \multicolumn{4}{|c|}{ Sharp-angled } & \multirow{2}{*}{$\begin{array}{c}\text { Rectangular } \\
30.1\end{array}$} \\
\hline & 107.7 & 45.0 & $30.1 \pm 0.1$ & 15.3 & \\
\hline \multicolumn{6}{|l|}{ Height (mm) } \\
\hline 30 & $1.8 \pm 0.1$ & $1.6 \pm 0.0$ & $1.6 \pm 0.2$ & $1.9 \pm 0.1$ & $2.2 \pm 0.1$ \\
\hline 20 & $1.9 \pm 0.1$ & $1.7 \pm 0.0$ & $1.8 \pm 0.2$ & $2.0 \pm 0.1$ & $2.2 \pm 0.1$ \\
\hline 10 & $2.1 \pm 0.1$ & $1.9 \pm 0.1$ & $1.9 \pm 0.2$ & $2.0 \pm 0.0$ & $2.3 \pm 0.1$ \\
\hline Average & $1.9 \pm 0.2$ & $1.8 \pm 0.1$ & $1.8 \pm 0.2$ & $2.0 \pm 0.1$ & $2.3 \pm 0.1$ \\
\hline Total average & \multicolumn{4}{|c|}{$1.9 \pm 0.2$} & $2.3 \pm 0.1$ \\
\hline
\end{tabular}

The $n$-values obtained are summarized in Table I for sharp-angled and rectangular frame types. Calculations were performed for three heights above the bulk liquid meniscus; a mean $n$-value for each frame is also given. We notice a clear decrease in $n$ with increasing height for frame legs with sharp-angled cross sections which is absent in the case of the frame with legs with rectangular cross sections. Furthermore the frame width seems to have little or no influence on $n$ : the mean $n$-value for all the frame widths with sharp-angled legs amounts to $1.9 \pm 0.2$, while for the frame with legs with rectangular cross sections it amounts to $2.3 \pm 0.1$.

\section{DISCUSSION}

The form of the frame legs appears to have an influence on the value of $n$ in Eq. [1]. Fig. 5 shows that for sharp-angled frame legs at large film thickness the thinning velocity $v_{\mathrm{t}}$ is smaller than for rectangular frame legs at the same thickness, while at small thicknesses the reverse holds true. A possible explanation is that the pressure gradient in the Plateau border is different for sharp-angled frame legs and for rectangular frame legs: deviations from the hydrostatic equilibrium pressure at a certain height are shown by measurements of the
Plateau border surface curvature (48). These pressure differences have been ascribed to Marangoni flows in the border at the border/ film transition and it is probable that these flows depend on the frame leg angle, because of its influence on the shape of the Plateau border and consequently on the surface to volume ratio at a certain height.

The following calculations refer to rectangular frame legs at a $10-\mathrm{mm}$ height above the bulk liquid, where in the border far from the border/film transition, hydrostatic equilibrium may be assumed, in agreement with the data reported in (48).

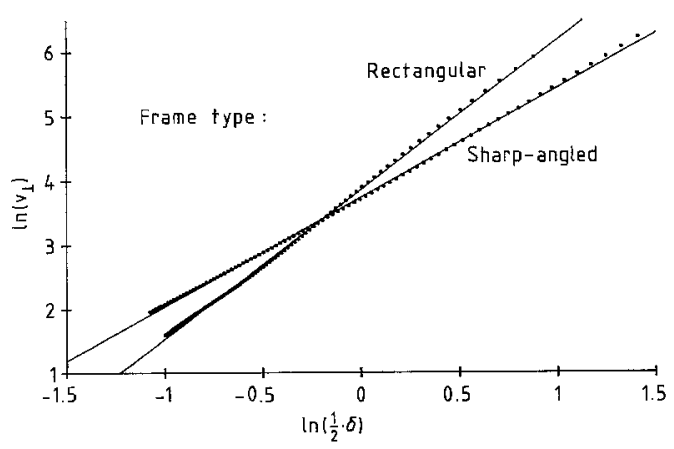

FIG. 5. The logarithm of the thinning rate $v_{\perp}$ as a function of the logarithm of the half film thickness $\delta / 2$ at a height of $10 \mathrm{~mm}$ for frames, respectively, with sharp-angled and with rectangular legs. 
In drainage caused by marginal regeneration, in the border/film boundary inflow regions alternate with outflow regions (1). We propose the following mechanism:

Small fluctuations in film thickness, e.g., induced by surface waves in vertical direction, are self-reinforcing. At a stationary border, with neither inflow into nor outflow from the film, a certain film thickness and border shape are mutually connected. A smaller local film thickness, with an unchanged border shape at some distance from the border/film transition, leads to inflow into the film, entailing a lower surface tension at this "primary inflow" spot compared with the surface tension in the surrounding film. The new film element therefore expands, the material being supplemented by further inflow from the border; in addition it rises because of hydrostatic forces. It pushes aside adjacent film elements, enlarging their thicknesses in the first instance. Such slightly larger thicknesses in between new film elements have indeed been observed (see under Experimental). This leads to outflow of these slightly thicker film elements into the border, which in turn facilitates entrance of new film elements from the border into the film at the primary inflow spot.

This mechanism can be quantified by an equation originally proposed by Frankel (1),

$$
Q=2 v_{\mathrm{s}} y+\frac{2 y^{3}}{3 \eta} \frac{d p}{d x},
$$

where $Q=$ volume flow out of or into the film, per unit length (the latter taken in the $z$-direction, see Fig. 6); $x=$ distance in the direction from some arbitrary point in the Plateau border, in the film direction; $y=$ half thickness of the Plateau border; $v_{\mathrm{s}}=$ surface velocity in the border, parallel to the surface; $\eta=$ viscosity; and $p=$ pressure.

The first term corresponds to the flow within the border per unit length, if the flow in the border were independent of $y$. The second term in [2] expresses the flow caused by the pressure gradient $d p / d x$. For the latter, Frankel substituted the Laplace pressure,

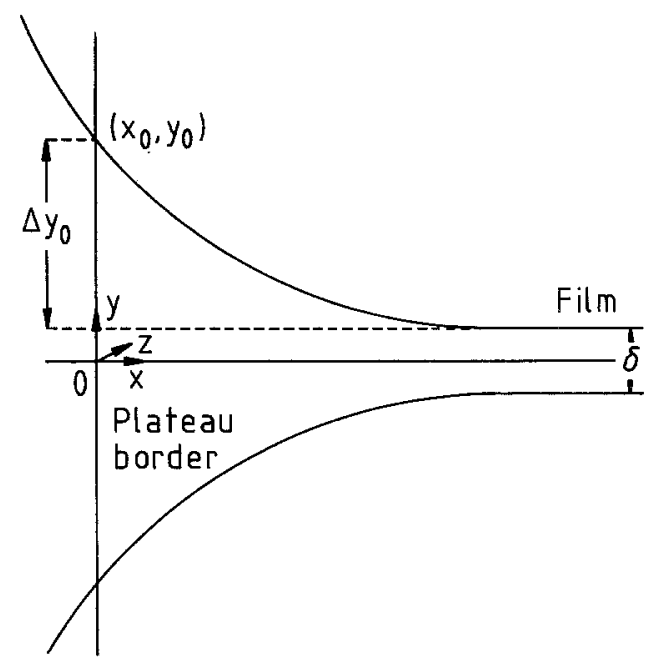

FIG. 6. Parameters in the theoretical description of flow by marginal regeneration (Eqs. [2]-[16]).

$$
\Delta p=\frac{\gamma}{r} \approx \gamma \frac{d^{2} y}{d x^{2}}
$$

with $\Delta p$ being the pressure difference between the Plateau border and environment, $\gamma$ the surface tension, and $r$ the radius of curvature, which is given by

$$
r=\frac{\left[1+(d y / d x)^{2}\right]^{3 / 2}}{d^{2} y / d x^{2}}
$$

Frankel arrived at Eq. [3] by assuming $\mid d y /$ $d x \mid \ll 1$ in Eq. [4]. For the pressure gradient, he arrived at

$$
\frac{d p}{d x}=\gamma \frac{d^{3} y}{d x^{3}},
$$

which involves the approximation that $\gamma$ is independent of $x$ (i.e., $\gamma=\gamma_{\text {bulk liquid }}$ ).

For stationary films, $Q$ and $v_{\mathrm{s}}$ were assumed by Frankel to be independent of $x$; thus

$$
Q=v_{\mathrm{s}} \delta .
$$

In this theory the surface tension is assumed to be constant. In view of our previous results this is improbable (48) and can be true only as a first approximation. However, no distinct horizontal transport causing such $\gamma$-differences was found. Apparently, these surface tension 
differences are compensated by pressure differences. In the analysis to follow, $\gamma$ as well as the pressure again is assumed to be constant, as a first approximation to a presumably much more complex situation. In addition, constancy of surface tension is assumed here only for a certain distance from the film into the border, viz., for that region of the border where upward flow occurs.

We avoided the restriction that $\mid d y / d x] \ll 1$ and obtained the relation

$$
\begin{aligned}
& \frac{d^{3} y}{d x^{3}}= \frac{3 \eta}{2 \gamma y^{3}}\left[v_{s}(\delta-2 y)\right. \\
&\left.+\frac{2 \gamma y^{3}}{\eta} \frac{(d y / d x)\left(d^{2} y / d x^{2}\right)^{2}}{\left[1+(d y / d x)^{2}\right]^{5 / 2}}\right] \\
& \\
& \quad \times\left[1+(d y / d x)^{2}\right]^{3 / 2}
\end{aligned}
$$

Equation [7] can be used for checking whether the mechanism proposed agrees with the experimental dependency of thinning velocity on $\delta$, as follows:

(i) At some point $\left(x_{0}, y_{0}\right)$ in the Plateau border (Fig. 6), the influence of the outflow of liquid from the film will have (practically) died away. We take $x_{0}=0$. The value of $y_{0}$ is one of the parameters which have to be chosen.

At this point, $d y / d x$ and $d^{2} y / d x^{2}$ have values which are independent of $Q$. For $d^{2} y / d x^{2}$ at this point, we take the value corresponding to the hydrostatic equilibrium curvature at the height concerned,

$$
\left(\frac{d^{2} y}{d x^{2}}\right)_{x=0}=\frac{\rho * g * z}{\gamma} *\left[1+\left(\frac{d y}{d x}\right)_{x=0}^{2}\right]^{3 / 2}
$$

where $\rho$ is the density, $g$ is the gravitational acceleration, and $z$ is the height above the bulk liquid meniscus; the results mentioned below are for a height of $10 \mathrm{~mm}$.

We first determine the profile of the Plateau border for $Q=0$ : assume a step $d x$ (e.g., 0.01 $\mu \mathrm{m}$ ) and a value for $(d y / d x)_{x=0}$ (which must be smaller than 0 in the situation chosen, see Fig. 6). Then $\left(d^{2} y / d x^{2}\right)_{x=0}$ is known, which gives $\left(d^{3} y / d x^{3}\right)_{x=0}$ according to Eq. [7]. We proceed by calculating the situation at $x=d x$ :

$$
\begin{gathered}
\left(\frac{d^{2} y}{d x^{2}}\right)_{x=d x}=\left(\frac{d^{2} y}{d x^{2}}\right)_{x=0}+\left(\frac{d^{3} y}{d x^{3}}\right)_{x=0} * d x \\
\left(\frac{d y}{d x}\right)_{x=d x}=\left(\frac{d y}{d x}\right)_{x=0}+\left(\frac{d^{2} y}{d x^{2}}\right)_{x=d x} * d x \\
y_{x=d x}=y_{x=0}+\left(\frac{d y}{d x}\right)_{x=d x} * d x
\end{gathered}
$$

This is repeated until $d y / d x=0$; the value of $y$ at this point is indicated by $y_{\min }$. The initial value of $(d y / d x)_{x=0}$ is then adjusted until $y_{\min }$ $=\frac{1}{2} * \delta$.

(ii) Next we calculate the border profile for $Q>0$ (i.e., where there is inflow from the border into the film). This will lead to a smaller value of the film thickness $(\delta$ $\left.-2 * \Delta y_{\text {in }}\right)$ at those points. It may come as a surprise that positive values of $Q$ and $v_{\mathrm{s}}$ lead to a smaller film thickness. This is a consequence of Eq. [7]: for $Q=0, v_{\mathrm{s}}=0$ (Eq. [6]), therefore $d^{3} y / d x^{3}$ is smaller than zero, according to Eq. [7], while $d^{2} y / d x^{2}$ is larger than zero. A positive value for $v_{\mathrm{s}}$ in Eq. [7] increases the absolute value of $d^{3} y / d x^{3}$ (because $\delta-2 * y<0)$. It therefore decreases $d^{2} y /$ $d x^{2}$ (Eq. [9]), which means a less increasing $d y / d x$, and thus leads to smaller $y$-values at given $x$-values, resulting finally in a smaller film thickness.

Assume a value for $\Delta y_{\text {in }}$ (e.g., 0.1 or 0.01 $\mu \mathrm{m})$ and adjust $v_{\mathrm{s}}$ in Eq. [6] to make $y_{\min }$ $=\frac{1}{2} * \hat{o}-\Delta y_{\text {in }}$. This gives a value for $Q_{\text {pos }}$, the inflow rate (per unit length in the $z$-direction) at those points on the border/film boundary.

(iii) We finally calculate the border profile for $Q<0$, i.e., for points at the border/film boundary where there is outflow from the film into the border. Here there is a local increase in the film thickness $\frac{1}{2} * \delta+\Delta y_{\text {out }}$, where $\Delta y_{\text {out }}$ is connected with $\Delta y_{\text {in }}$, e.g., by the conditions

$$
\begin{aligned}
& \Delta y_{\text {out }} * d z_{\text {out }}-\Delta y_{\text {in }} * d z_{\text {in }}=0 \\
& d z_{\text {out }} / d z_{\text {in }}=1 .
\end{aligned}
$$

$d z_{\text {out }}$ and $d z_{\text {in }}$ are fractions of unit lengths in 
the $z$-direction, in which outflow or inflow occurs. Application of Eq. [12] is equivalent to the assumption that marginal regeneration is caused by thickness fluctuations in the film, in which there is no net flow in the $x$-direction; once formed these thickness fluctuations persist although they cause movements in the $x$ direction (liquid flow out of, or into, the film). This persistence of thickness fluctuations is suggested by the interference colors of the film (see also Ref. (7)), which show, near the film / Plateau border, transition regions of lower thickness alternating with regions of larger thickness than the normal thickness at a certain height; the latter remain for some time. The assumption underlying Eqs. [12] implies that the necessary adjustments of the adjoining Plateau border are accompanied by net liquid transport in the $z$-direction. (Otherwise, $\int y * d x$ should have been assumed to be constant instead of relations [12].) The assumption underlying Eqs. [12] can, however, easily be defended, because in the Plateau border there is pronounced transport in the $z$-direction (48).

Given a reasonable assumption for the value of $d z_{\text {out }} / d z_{\text {in }}$, e.g., taken to be $1, \Delta y_{\text {out }}$ can then be found and a value for $Q_{\text {neg }}$, the outflow rate (per unit length in the $z$-direction) in outflow regions of the border/film boundary, can be obtained.

The net outflow rate can then be found by

$$
Q_{\text {net }}=Q_{\text {pos }} d z_{\text {in }}+Q_{\text {neg }} d z_{\text {out }} .
$$

If we neglect the vertical drainage in the film, as proposed by Mysels et al. (1), conversion of the net outflow rate to the surface velocity $v_{\perp}$ in the direction perpendicular to the plane of the film, as calculated from the experimental film profiles, is performed by

$$
Q_{\text {net }}=v_{\perp} b
$$

where $b$ is the total width of the glass frame, and the factor 2 for the two surfaces is compensated by the factor $\frac{1}{2}$ for the half frame width, from which the draining liquid originates.

This set of equations assumes that $Q_{\text {net }}$ at a certain level is connected with inflow and outflow at the same level. This is not exactly true, since thinner film elements formed by marginal regeneration move to parts of the film where thicknesses match, i.e., to larger heights, and therefore influence $Q_{\text {net }}$ at a different height. Equations [13] and [14] in fact neglect the height difference between adjacent inflow and outflow regions, which is, however, considered to be a second-order effect.

This gives the outflow of liquid for various film thicknesses with parameters $\Delta y_{0}$ ( $y_{0}$ $\left.-\frac{1}{2} \delta\right), \Delta y_{\text {in }}$, and $d z_{\text {out }} / d z_{\text {in }}$. It appears that variations in $d z_{\text {out }} / d z_{\text {in }}$ do not greatly influence the results. The value of $\Delta y_{\text {in }}$ determines the absolute value of the net liquid flow, but does not influence the dependence of the liquid flow on the film thickness. The latter is, however, distinctly influenced by $\Delta y_{0}: n$ in Eq. [1], derived from the logarithmic thinning rate vs the logarithmic film thickness curves by differentiation, at a given film thickness, decreases with increasing $\Delta y_{0}$.

The data on which these conclusions are based have been calculated on the assumptions

$$
\begin{aligned}
& v_{\mathrm{s}}=v_{\mathrm{s}, \mathrm{f}} \exp \left[-\alpha\left(x_{\min }-x\right)\right] \\
& Q=Q_{\mathrm{f}} \exp \left[-\alpha\left(x_{\min }-x\right)\right]
\end{aligned}
$$

i.e., with an exponentially decaying surface velocity and volume drainage rate decaying with the same constant $\alpha, v_{\mathrm{s}, \mathrm{f}}$ is the surface velocity at the border/film transition and $Q_{\mathrm{f}}$ is the volume flow at this point. This was thought to be more realistic than Frankel's assumption that $v_{\mathrm{s}}$ and $Q$ are constant. In the context of the present paper, Frankel's assumption comes down to the assumption that $v_{\mathrm{s}}$ and $Q$ are independent of $x$ for $0<x<x_{\min }$ (where $x_{\min }$ is the $x$-value at the border/film transition), but suddenly drop to zero at $x$ $=0$. The decay constant $\alpha$ was calculated on the assumption that $v_{\mathrm{s}}=v_{\mathrm{s}, \mathrm{f}} / 12,000$ at $x=0$. 
This leads to

$$
\begin{aligned}
\frac{d^{3} y}{d x^{3}}= & \frac{3 * \eta}{2 * \gamma * y^{3}} *\left\{v_{\mathrm{s}, \mathrm{f}} *(\delta-2 * y)\right. \\
& * \exp \left[-\alpha *\left(x_{\min }-x\right)\right] \\
& \left.+\frac{2 * y^{3}}{\eta} * \gamma * \frac{d y / d x *\left(d^{2} y / d x^{2}\right)^{2}}{\left[1+(d y / d x)^{2}\right]^{5 / 2}}\right\} \\
& *\left[1+\left(\frac{d y}{d x}\right)^{2}\right]^{3 / 2}
\end{aligned}
$$

instead of Eq. [7]. This can be derived directly by introducing Eqs. [15] and [16] into Eq. [2]. It was found that the assumption of a constant $v_{\mathrm{s}}$ (according to Frankel's original view) leads to similar values of the exponent $n$ as the exponential decay assumed here, although $\Delta y_{0}$ has to be chosen at larger values on the assumption of exponentially decaying $v_{\mathrm{s}}$ and $Q$, in order to lead to $n$-values agreeing with those calculated from the experimental data. Figure 7 shows the exponent $n$ as a function of the film thickness for various values of $\Delta y_{0}$ and $\Delta y_{\text {in }}$. The values for $n$ are derived from the double-logarithmic plots of the thinning rate $v_{\perp}$ as a function of film thickness by differentiation. The experimental results are well described with $6 \mu \mathrm{m}<\Delta y_{0}<12 \mu \mathrm{m}$ for the rectangular frame, while for the sharp-angled frames a $\Delta y_{0}$ larger than $12 \mu \mathrm{m}$ has to be assumed. The calculated values of $n$ do not

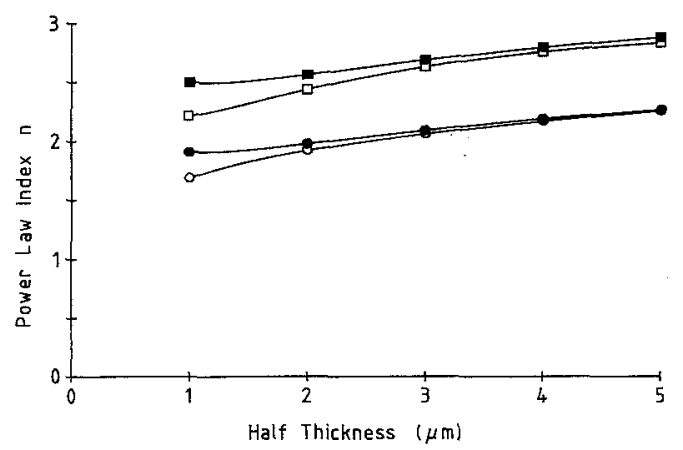

FIG. 7. Power law index ( $n$ ) values (Eq. [1]) calculated by theory as a function of half thickness of the film $(\delta /$ 2). Open symbols: $\Delta y_{\text {in }}=0.01 \mu \mathrm{m}$. Closed symbols: $\Delta y_{\text {in }}$ $=0.1 \mu \mathrm{m}$. $O, \Delta: \Delta y_{0}=24 \mu \mathrm{m} ; \square, \mathbf{E}: \Delta y_{0}=6 \mu \mathrm{m}$. strongly depend on $\Delta y_{\text {in }}$ as long as $\Delta y_{\text {in }}$ is taken to be independent of film thickness (Fig. 7). On the other hand, the assumption of a thickness fluctuation which is proportional to film thickness (e.g., $\Delta y_{\text {in }}=0.1 * \delta$ ) leads to $n$-values which are substantially larger $(\approx 4)$ than those found experimentally.

In this analysis it is assumed that all drainage is due to horizontal transport. Fig. 2 shows that this is a good approximation of the case but is not exact. This might introduce an error into the $n$-values found by differentiating curves like those in Fig. 3. However, this is a small effect only; in addition, the $v_{\perp}$-values extrapolated to $1 / b \rightarrow 0$ (corresponding to infinite film width, thus the absence of horizontal transport) have about the same $n$-values (between 1.5 and 3 ) as those found for the $v_{\perp}$ values calculated for finite $b$-values. Therefore no significant error is introduced.

Upon comparison with the experimental data (Fig. 4 and Table I), we find

(a) The $n$-values calculated through Eq. [16] tend to increase with increasing film thickness for constant $\Delta y_{0}$. The experimental data do not permit us to confirm or to reject such an increase of $n$ with film thickness. In Table I constant (i.e., thickness independent) average $n$-values are mentioned, which are best compared with average theoretical $n$ values.

(b) For a frame with rectangular legs, agreement between experiment and theory is good, if $\Delta y_{0}$ is between 6 and $12 \mu \mathrm{m}$. For the frame with the sharp-angled legs, larger values of $\Delta y_{0}$ have to be assumed.

(c) The computed thinning velocities $v_{\perp}$ for a glass frame $30 \mathrm{~mm}$ in width and at an altitude of $10 \mathrm{~mm}$ above the bulk meniscus are in the same range as those calculated from the experiments. The exact values, however, depend on the value of $\Delta y_{0}$.

\section{CONCLUSIONS}

Drainage of vertical mobile free liquid films can be described satisfactorily given the following assumptions: 
(a) horizontal drainage predominates;

(b) the net flow out of the film is the result of a surface flow combined with a bulk flow caused by a pressure gradient;

(c) at some place at which the half thickness of the Plateau border is about $9 \mu \mathrm{m}$ larger than that of the film, surface flow and volume flow both have died away;

(d) marginal regeneration is caused by thickness fluctuations in the film with little or no flow in the $x$-direction; these thickness fluctuations persist once marginal regeneration leads to flow in the $x$-direction;

(e) The fluctuations are of the order of 0.1 $\mu \mathrm{m}$, independent of film thickness.

\section{SUMMARY}

Results of calculations on the profiles of vertical mobile free liquid films measured interferometically, in which the net flow out of the film is a combination of surface flow and bulk flow caused by a pressure gradient, confirmed the existing hydrodynamic theory on marginal regeneration. Qualitatively, this theory explains the thinning of a mobile film by the exchange by the Plateau border of thicker film parts, including the surfaces, for thinner parts in the immediate vicinity.

\section{REFERENCES}

1. Mysels, K. J., Shinoda, K., and Frankel, S., in "Soap Films: Studies of their Thinning and a Bibliography" Pergamon, Elmsford, NY, 1959.

2. Scheludko, A., Kolloid Z. 155, 39 (1957).

3. Scheludko, A., Adv. Colloid Interface Sci. 1, 391 (1967).

4. Radoev, B. P., Scheludko, A. D., and Manev, E. D., J. Colloid Interface Sci. 95, 254 (1983).

5. Mysels, K. J., and Cox, M. C., J. Colloid Sci. 17, 136 (1962).

6. Lyklema, J., Rec. Trav. Chim. 81, 890 (1962).

7. Mysels, K. J., J. Phys. Chem. 68, 3441 (1964).

8. Lyklema, J., Scholten, P. C., and Mysels, K. J., J. Phys. Chem. 69, 116 (1965).

9. Duyvis, E. M., and Overbeek, J. Th. G., Proc. K. Ned. Akad. Wet. Ser. B 65, 26 (1962).

10. Duyvis, E. M., thesis, Utrecht, 1962.
11. Lyklema, J., and Mysels, K. J., J. Amer. Chem. Soc. 87, 2539 (1965).

12. Jones, M. N., Mysels, K. J., and Scholten, P. C., Trans. Faraday Soc. 62, 1336 (1966).

13. Clunie, J. S., Corkill, J. M., and Goodman, J. F., Discuss. Faraday Soc. 42, 34 (1966).

14. Prins, A., and Van den Tempel, M., Spec. Discuss. Faraday Soc. 1, 20 (1971).

15. Clunie, J. S., Corkill, J. M., Goodman, J. F., and Ingram, B. T., Spec. Discuss. Faraday Soc. 1, 30 (1971).

16. Bruil, H. G., and Lyklema, J., J. Electroanal. Chem. 37, 31 (1972).

17. Ingram, B. T., J. Chem. Soc. Faraday Trans. I 68, $2230(1972)$.

18. Yamanaka, T., Bull. Chem. Soc. Japan 48, 1755 (1975).

19. Yamanaka, T., Bull. Chem. Soc. Japan 48, 1760 (1975).

20. Donners, W. A. B., thesis, Utrecht, 1976.

21. Agterof, W. G. M., thesis, Utrecht, 1977.

22. McEntee, W. R., and Mysels, K. J., J. Phys. Chem. 73, 3018 (1969).

23. Frankel, S., and Mysels, K. J., J. Phys. Chem. 73, 3028 (1969).

24. Mysels, K. J., and Stikeleather, J. A., J. Colloid Interface Sci. 35, 159 (1971).

25. Frens, G., Mysels, K. J., and Vijayendran, B. R., Spec. Discuss. Faraday Soc. 1, 12 (1971).

26. Princen, H. M., J. Phys. Chem. 72, 3342 (1968).

27. Prins, A., J. Colloid Interface Sci. 29, 177 (1969).

28. Frankel, S., and Princen, H. M., J. Phys. Chem. 74, 2580 (1970).

29. Princen, H. M., and Frankel, S., J. Colloid Interface Sci. 35, 386 (1971).

30. Mysels, K. J., and Buchanan, J. W., J. Electroanal. Chem. 37, 23 (1972).

31. De Feijter, J. A., and Vrij, A., J. Colloid Interface Sci. 64, 269 (1978).

32. Vrij, A., Discuss. Faraday Soc. 42, 23 (1966).

33. Vrij, A., and Overbeek, J. Th. G., J. Amer. Chem. Soc. 90, 3074 ( 1968).

34. Felderhof, B. U, J. Chem. Phys. 49, 44 (1968).

35. Lucassen, J., Van den Tempel, M., Vrij, A., and Hesselink, F. Th., Proc. K. Ned. Akad. Wet. Ser. B 73, 109 (1970).

36. Vrij, A., Hesselink, F. Th., Lucassen, J., and Van den Tempel, M., Proc. K. Ned. Akad. Wet. Ser. B 73, 124 (1970).

37. Joosten, J. G. H., Vrij, A., and Fijnaut, H. M., in "Physicochemical Hydrodynamics" (D. B. Spalding, Ed.), Vol. II. V. G. Levich Festschrift/Imp. Coll. Sci. Technol., London/Advance Publications, Ltd. (1977).

38. Joosten, J. G. H., thesis, Utrecht, 1982.

39. Sharma, A., and Ruckenstein, E., Langmuir 2, 480 (1986). 
40. Ruckenstein, E., and Sharma, A., J. Colloid Interface Sci. 119, 1 (1987).

41. Sharma, A., and Ruckenstein, E., J. Colloid Interface Sci. 119, 14 (1987).

42. Sharma, A., and Ruckenstein, E., Colloid Polym. Sci. 266, 60 (1988).

43. Mysels, K. J., Cox, M. C., and Skewis, J. D., J. Phys. Chem. 65, 1107 (1961).

44. Roberts, K., Axberg, C., Osterlund, R., and Saito, H., Nature (London) 255, 53 (1975).

45. Von Wandruszka, R, and Winefordner, J. D., Talanta 33, 871 (1986).

46. Koczo, K., and Racz, G., Colloids Surf. 22, 97 (1987).
47. Highfield, R. R., Humes, R. P., Thomas, R. K., Cummins, P. G., Gregory, D. P., Mingins, J., Hayter, J. B., and Schaerpf, O, J. Colloid Interface Sci. 97, 367 (1984).

48. Hudales, J. B. M., and Stein, H. N., J. Colloid Interface Sci., submitted for publication.

49. Vassiliades, A. E., in "Cationic Surfactants" (E. Jungerman, Ed.), Ch. 12. Dekker, New York, 1970.

50. Mysels, K. J., personal communication, 1989.

51. Hoerl, A. E., Nashed, M. Z., McKetta, J. J., and Silberberg, J. H., in "Perry's Chemical Engineer's Handbook" (D. W. Green and J. O. Maloney, Eds.), 6th ed., pp. 2-65. McGraw-Hill, New York, 1984. 